\title{
明确三个目标定位全面推进建材行业和水泥工业生态 环保绿色发展
}

\author{
尚再国* 何俊秀 刘小龙 韩博文 吴 亮
}

永登祁连山水泥有限公司, 甘肃 730301

摘 要: 随着我国各项资源的不断缩减, 现阶段, 我国政府部门已经极为重视节能减排工作的发展情况, 并且正 在积极努力的引导各类能源消耗较大的产业进行绿色化改革, 其最终目的就在于有效地促进我国环保事业的发展, 提 升各项资源的有效利用率, 避免资源浪费问题出现。此次研究主要就全面推进建材行业和水泥工业生态环保绿色发展 做了简要的分析，目的在于进一步推进我国节能减排计划的实施。

关键词：建材行业；水泥工业；生态环保；绿色发展；措施

\section{一、前言}

从宏观的角度分析, 现阶段, 促进产业绿色化改革推进节能减排计划是目前我国重要的发展战略方针, 同时也是 我国实现可持续发展目标最重要的一环 ${ }^{[1]}$ 。现阶段, 在我国政府部门的大力倡导以及扶持下, 诸多行业已经有效地完 成了绿色化转型, 都有效的革新了生产技术, 建材行业也不例外, 建材行业相对于其他行业而言属于资源使用量较大 的一个行业, 尤其是水泥工业, 水泥作为建筑工程行业不可或缺的一种物资, 如果能够有效地实现水泥工业的生态环 保绿色化改革发展目标，那么对于我国的节能减排计划实施将有着较强的辅助促进作用。

\section{二、明确三个目标定位全面推进建材行业和水泥工业生态环保绿色发展}

从现实的角度分析, 在建材行业当中水泥属于最为重要的一种建筑原材料, 而要想有效地促进建材行业生态环保 绿色发展, 可以以水泥工业为切人点进行具体的绿色改革发展工作, 有效地实现水泥工业生态环保绿色发展, 不仅可 以极大地提升当前建材企业的能源消耗量，同时还可以有效地提升建材行业的社会形象，进而促进建筑工程企业进一 步发展 ${ }^{[2]}$ 。随着我国水泥工业管理者对于生态环保绿色发展研究的不断深人, 经过长时间的实践研究发现, 要想有效 地实现既定发展目标，需要明确三个目标定位。

（一）认识定位以及目标定位

具体而言, 就是水泥工业要有效的将节能减排计划以及智能化发展计划融人企业的发展战略当中，同时还要依照 节能减排计划设置出相关的生产标准, 保证粉尘、二氧化硫以及氮化物的排放指标不得超过的具体数值。另外, 还需 要与城市垃圾处理部门以及废弃物回收部门有效的做好城市垃圾处理工作，降低生产废弃物的排放量。

（二）要严格践行节能减排计划, 并有效地将其上升到企业系统工程的高度

积极努力的研发新型的生产技术以及生产设备，并在此基础上以国家政策为导向，制定出具有针对性地企业内胃 部管理制度, 将节能减排融人企业文化体系当中，有效地提升落后产业准人门槛的高度，全面优化水泥工业结构以及 产品结构 ${ }^{[3]}$ 。

（三）要有效地进行发展方式以及产业增长模式变革

构建出增减有度的结构, 为实现节能减排计划奠定坚实的基础, 要有效的淘汰一些落后的产业以及污染程度较为 严重的产业，对于一些重要的产业要鼓励其进行转型发展，同时还要制定出相关的法律法规，以及建材产业转型指导 发展意见, 为建材产业及水泥工业的生态环保绿色化发展提供必要的理论支持, 并在此基础上有效地提升该种行业的 产业形象。下图1为水泥生产流程图。

“通讯作者：尚再国，1967年1月，男，汉族，甘肃环县人，就职于永登祁连山水泥有限公司，高级工程师，大 专。研究方向：机电一体化。 


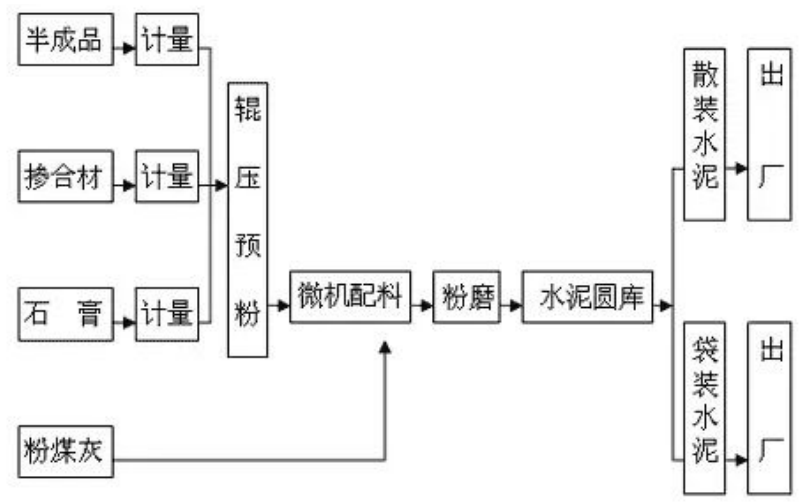

图1 水泥生产工艺图

\section{三、全面推进建材行业和水泥工业生态环保绿色发展的阻碍问题}

现阶段, 我国建材行业管理者及水泥生产企业内部管理人员都极为重视产业的生态环保绿色化发展工作, 随着研 究的深人度不断提升, 逐渐发现目前现阶段, 水泥工业及建材行业在实践进行生态环保绿色化转型的过程当中仍然存 在着诸多较为显著的问题, 而这些问题如果未得到及时有效地解决, 那么水泥工业将很难实现既定绿色化改革发展目 标，这些问题集中表现在多个方面。

（一）企业内部缺乏专业的绿色改革计划推进管理团队

相关的管理人员过于重视企业整体经济收益的提升, 缺乏生态环保意识, 对于节能减排计划的认知度较低, 同时 由于没有接受过专业的培训使其对于各项新型绿色化生产技术的掌握熟练度较低 ${ }^{[4]}$ 。

(二) 缺乏针对节能减排计划实施的管理制度体系

企业内部的发展管理制度相对较为笼统，没有针性。

（三）对于企业生态环保绿色发展信息的宣传力度较低

没有有效的将绿色环保元素融人企业文化当中, 从而导致企业的绿色化改革发展速度一直很难得到提升。下图2 为水泥加工处理图。

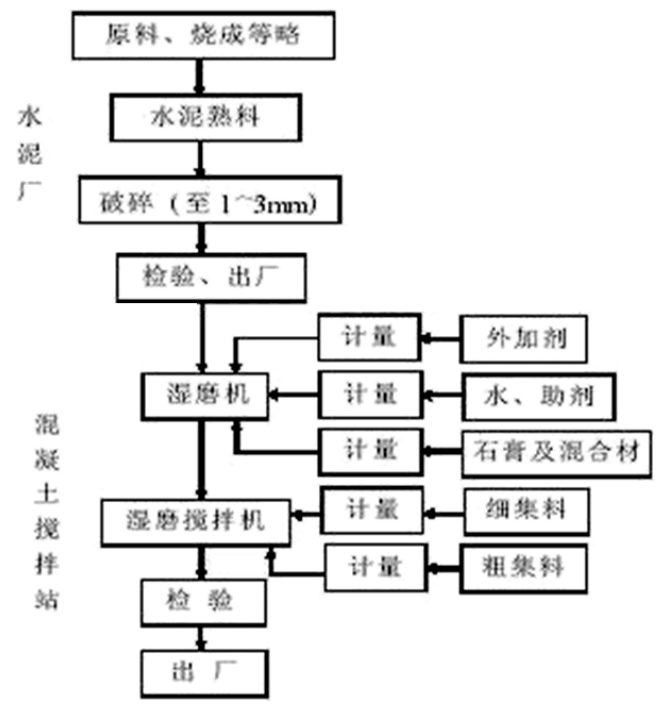

图2 水泥加工处理图

四、全面推进建材行业和水泥工业生态环保绿色发展的有效措施

(一) 提升企业管理层的环保意识

企业内部的管理人员是各项生产管理以及发展战略计划制定工作的第一执行者, 其综合素质水平在一定程度上直 接影响水泥生产企业能否实现既定绿色化改革目标, 进而影响到建材行业及水泥工业生态环保绿色发展目标能否实 
现。因此, 水产业内部的管理层自身需要关注产业绿色化转型信息 ${ }^{\left[{ }^{[}\right]}$。

1. 企业内部的管理人员需要积极定的探究国家所出台的节能减排计划及相关扶持政策，同时还要明确节能减排计 划实施对于企业可持续发展的重要性。

2. 企业的管理层要积极主动的参加各项培训活动为员工作好模范带头作用, 在实践培训期间要积极主动地学习一 些节能减排计划实施要点、水泥工业绿色化转型发展路径、建材行业绿色发展方向、各类绿色化生产技术、绿色环保 意识、创新管理能力等。保证其自身的综合素质水平能够支撑建材行业及水泥工业生态环保绿色发展工作的需求。

3. 水泥工业领导者还要定期的组织负责管理工作的人员开展工作研讨会, 在会议当中明确指出企业未来的发展目 标就是践行节能减排计划实现绿色化转型目标, 并设置出具体的生产指标及防污染指标, 然后引导各个部门的管理人 员表述出可能出现的问题。

（二）健全企业绿色化转型管理制度

建材行业及水泥工业在进行生态环保绿色发展的过程当中需要配以相适的制度体系作为支持, 只有在针对企业绿 色化转型发展的制度支持下，才能够保证各项发展工作的规范性以及秩序性 ${ }^{[6]}$ 。

1. 相关的管理人员在实际工作期间必须有效地实施奖惩制度, 明确对于企业绿色化转型发展工作有突出贡献, 并 提出相关具有可行性的转型发展意见的人员，不论是企业员工还是管理层都会享受到企业的奖励，而对于在工作期间 不作为, 时常做出违背绿色发展理念行为的部门管理者及员工都要基于一定的惩罚，引导企业内部员工相互监督。

2. 要有效落实连带责任追究管理制度, 明确水泥生产企业内部各个部门管理者所应承担的责任, 将绿色化转型发 展工作进行细致的划分, 同时还要设置出节能减排指标, 一旦出现问题如果发展是人为原因导致的, 那么就需要追究 相关负责人的具体责任 ${ }^{[7]}$ 。

3. 需要实施信息披露制度, 依照国家相关规定, 有效地披露企业的防污工作信息, 节能减排计划实施信息以及各 项财务信息，保证企业发展的透明度以及规范性，是社会群众也能够成为监督水泥工业绿色化发展的主体 ${ }^{[8]}$ 。

（三）强化对于建材行业及水泥工业生态环保绿色发展信息宣传力度

我国建材工业总的能耗和排放多少年来处在全国工业系统的前两位和前三位之间, 其中二氧化硫占全国排放总 量的 $10.3 \%$ ，氮氧化物占全国排放总量的 $13.9 \%$ ，烟尘排放占全国排放总量的 $16 \%$ ，废弃物排放总量占全国排放总量的 $13.2 \%$ 。虽然近几年建材行业节能减排各项指标都有明显的进步, 但是整个工业系统大家都在进步, 因此占的比例没 有发生多大的变化。水泥工业绿色化转型发展需要产业管理人员的高度重视才能够顺利实施, 而影响企业管理人员对 于该项信息重视度的关键影响因素就是对于建材行业及水泥工业生态环保绿色发展信息宣传力度高低。

1. 政府部门需要积极努力的引导水泥工业与社会媒体部门合作, 构建出合作共同体, 有效地宣传一些关于水泥工 业绿色化转型发展信息以及相关的绿色化生产技术和节能减排计划实施的重要性信息 ${ }^{[9]}$ 。

2. 水泥工业要将节能减排元素融人企业文化当中, 引导各个生产部门负责人在保证产量的同时也必须重视生态环 保工作。

\section{五、结束语}

综上所述，现阶段我国政府部门正在积极努力的倡导工业产业进行绿色化改革，从而有效地降低我国的资源消耗 量, 实现可持续发展目标。而建材行业内水泥工业必须做到积极响应政府部门号召, 有效地进行绿色化改革发展工 作。从实际角度出发, 水泥工业的年资源消耗量相对较高, 如果水泥工业能够有效地实现绿色化改革目标, 降低资源 的消耗量, 不仅对于我国可持续发展有着重要的意义, 同时还可以有效的起到带头作用, 带动建材行业进行绿色化生 产转型。但是目前由于一些较为显著的阻碍性问题没有得到解决, 导致建材行业及水泥工业都很难实现既定绿色化改 革目标，进而导致节能减排计划无法持续有效地进行下去。基于这一情况，企业内部的管理人员在实践工作期间必须 重视对于基于三个目标下的推进建材行业及水泥工业生态环保绿色化转型发展的研究, 有效地掌握三个目标的具体内 容, 分析现阶段存在于产业当中的问题结合这些问题制定出具有针对性地解决措施, 以此来保证水泥工业及建材行业 能够很好地推动节能减排计划的实施。

\section{参考文献:}

[1]庄毅敏.江苏省建材行业协会和省工信厅原材料处联合召开水泥工厂设备智能化管理座谈会 [J].江苏建材, 2019(06):72. 
[2]王国祥.云南水泥建材集团举办“智慧昆钢”协作云平台操作培训[J].建材发展导向,2019,17(24):70.

[3] 本刊记者. 加快水泥窑协同处置推广发展坚定不移走绿色生态健康发展之路一一访中国建材联合会副会长陈国 庆[J].中国建材, 2018(02):26-29.

[4]本刊讯. 向环保产业转型走绿色发展之路中国建材联合会将召开全国水泥窑协同处置创新发展大会 [J].中国建 材, 2017(06):65.

[5]张秀前.研究绿色建材与水泥工业的可持续发展[J].门窗, 2016(11):51.

[6]张军.散装水泥在绿色建材中的地位和作用——泰安市散装水泥绿色产业发展纪实[J].散装水泥, 2016(05):34-38.

[7]唐黎标.水泥砤如何向绿色建材转化[J].上海建材, 2015(06):25-26.

[8]庄毅敏.江苏省建材行业协会和省工信厅原材料处联合召开水泥工厂设备智能化管理座谈会 $[\mathrm{J}]$. 江苏建 材,2019(06):72.

[9]王玲娟,江昔平.再生混凝土作为绿色建筑材料的基本性能与发展趋势 [J].四川建材, 2014,40(04):26-28. 